\title{
ALLOY 706 USE, PROCESS OPTIMIZATION, AND FUTURE DIRECTIONS FOR GE GAS TURBINE ROTOR MATERIALS
}

\author{
Peter W. Schilke and Robin C. Schwant \\ GE Power Systems \\ Material and Processes Engineering \\ 1 River Road \\ Schenectady, NY 12345
}

\begin{abstract}
The use of Alloy 706 in GE Gas Turbines is described from the initial application in the first F class machines to today's current Advanced F class machines. The process optimization that has occurred during the last decade of use is described. This includes compositional optimization, processing refinements, and improvements in ultrasonic inspection techniques. The future directions for Heavy Duty Industrial Gas Turbine rotor materials and processes is also outlined. This materials and processes work has contributed to the achievement of the most reliable $\mathrm{F}$ class gas turbine in the world and will continue to provide growth capability for the next generation of GE machines.
\end{abstract}

Superalloys 7 18, 625.706 and Various Derivatives

Edited by E.A. Loria

TMS (The Minerals. Metals \& Materials Society). 2001 


\section{Introduction of 706 into Gas Turbine Application}

History of Alloy Investigations

Alloy 706, a nickel-iron superalloy, evolved from studies performed at the International Nickel Company (INCO) in the 1950's "1) and was patented in 1972. The alloy was originally developed as a higher strength main steam piping material for super critical steam power plants which were being planned by U.S. utilities at that time. The nominal chemistry of alloy 706 and its betterknown sister alloy, 718 , are shown in Table 1.

Table I: Nominal Chemistries of Alloy 706 and 718

\begin{tabular}{|l|l|l|l|l|l|l|l|l|l|l|}
\hline Alloy & \multicolumn{1}{l|}{$\mathrm{C}$} & $\mathrm{Mn}$ & $\mathrm{Si}$ & $\mathrm{Cr}$ & $\mathrm{Ni}$ & $\mathrm{Fe}$ & $\mathrm{Ti}$ & $\mathrm{Al}$ & $\mathrm{Mo}$ & $\mathrm{Cb}$ \\
\hline 706 & 0.03 & 0.20 & 0.20 & 16.0 & 41.5 & 40.0 & 1.8 & 0.2 & & 2.9 \\
\hline 718 & 0.04 & 0.20 & 0.20 & 19.0 & $\mathbf{5 2 . 5}$ & 18.5 & 0.9 & 0.5 & 3.0 & 5.1 \\
\hline
\end{tabular}

Alloy 706 was first considered for turbine application by GE in the mid 70's. A development program was conducted to assess the feasibility of making large industrial gas turbine Alloy 706 wheels and to determine the resultant properties ${ }^{2}$. The ingot, produced by the ESR process, measured approximately 24 inches in diameter by about 90 inches long and weighed 11,700 pounds. The forge practice consisted of an initial upset, a draw, a second upset and a final forge operation.

The wheel was machined and sectioned. Portions of the wheel were given either a two or a three step aging heat treatment. The wheel sections were ultrasonically tested and no indications were found. This program showed that a large Alloy 706 ingot could be successfully made, forged into a large wheel shape, and heat-treated to achieve good property levels. It was almost ten years later when this initial work was continued to develop and qualify alloy 706 forgings for a new class of gas turbines.

The "F" machine with an introductory firing temperature of $\sim 2250 \mathrm{~F}(1230 \mathrm{C}$ ), was developed by GE in the late 80 's ${ }^{(3)}$. Because this machine operated at a firing temperature more than 250 $\mathrm{F}(140 \mathrm{C})$ higher than the previous generation of industrial gas turbines, and because cooled compressor discharge cooling air would be required to use the existing wheel materials, alloy 706 was chosen for use in the wheels and spacers. Prior to this, all the turbine wheels had been made from steel.

\section{$\underline{\text { Rationalfor alloy } 706 \text { Selection }}$}

Aircraft engines used high strength nickel based superalloys for many years prior to the introduction of the " $F$ " machine. The alloys used in aircraft application can be classified as either $\gamma^{\prime}\left(\mathrm{FCC}, \mathrm{Ni}_{3}[\mathrm{Al}, \mathrm{Ti}]\right)$ or $\gamma^{\prime \prime}\left(\mathrm{BCT}, \mathrm{Ni}_{3} \mathrm{Cb}\right)$ strengthened alloys. One of the reasons for selecting alloy 706 for the " $F$ " machine was the slow growth kinetics of the $\gamma$ " strengthening phase. Superalloys that harden through the formation of $\gamma^{\prime \prime}$ are more suitable for components with large cross sections because over-aging will not occur during heat treatment. If large landbased turbine wheels were made from $\gamma^{\prime}$ strengthened alloys, the over-aging that would occur during cooling from heat treatment would cause the alloy to lose much of its strength ${ }^{(t)}$. 
Alloy 706 was selected for this application also because of its good mechanical properties, ease of fabrication, and good machinability. A review of commercial alloys showed that only alloy 706 and alloy 718 possessed the required strength at temperature for the " $F$ " class machines. The ability to produce large ingot diameters was also a necessity. Ingot diameters exceeding 30 inches were required to avoid exceeding the ingot's length-to-diameter ratio (approximately $3: 1$ ) where buckling of the ingot may occur during upsetting. The maximum diameter ingot that had been made of alloy 718 at this time without freckling was approximately 24 inches and largest ingot used for rotating aircraft components was only 20 inches. Above this size it was believed that freckle segregation would occur. However, previous good experience (summarized below) had been documented with Alloy 706 in sizes up to almost 12,000 pounds and it was believed that up to 30-inch electro-slag remelted (ESR) ingots could easily be made. In addition, alloy 706 had substantially better machinability than Alloy $718^{(5)}$.

\section{Turbine Application}

The turbine rotor design of all General Electric heavy-duty land-based gas turbines is a bolted construction of forged turbine wheels, spacers and stub shafts. While a few turbine designs utilized M-152 steel as the turbine wheel material at that time, most designs used CrMoV low alloy steel turbine wheels. Low alloy steel has been used extensively in heavy-duty gas turbine designs because this low cost, easily fabricated material can handle high stresses at relatively low temperatures. However, the " $F$ " machine compressor discharge temperature increased by $\sim 50 \mathrm{~F}(28 \mathrm{C})$ relative to the previous " $\mathrm{E}$ " class of turbines due to increased compressor ratio. The annulus area of the last stage of the turbine was also increased by the use of larger last stage buckets. These changes resulted in higher operating temperatures and stresses in the turbine rotor structure, and dictated the requirement for a better turbine wheel material.

The larger annulus and heavier blades of the $\mathrm{F}$ turbines created a need for ingots weighing up to $33,000 \mathrm{lbs}(15,000 \mathrm{~kg}){ }^{(3)}$. This lead to production of ingots up to 40 " in diameter due to a desire to limit the length to diameter ratio of the ingot to $-3: 1$ to avoid buckling during upset forging. Some early work was done with double melted alloy 706 material. Both vacuum induction melting followed by electroslag re-melting (VIM/ESR) and vacuum induction melting followed by vacuum are re-melting (VIM/VAR) material was evaluated. It was found that the double melted VLM/ESR material had freckles and macro segregation that could not be eliminated by any practical thermo-mechanical process or homogenization heat treatment. Figure 1 shows a VIM/ESR forging containing freckles that appear as dark spots on the surface and that follow the forging flow lines in cross-section. These freckles contain a high density of precipitates including laves phase, carbides and nitrides ${ }^{(7)}$. Laves phase contains a much higher concentration of columbium, Table 2. In a finish forged and heat treated material cracks are often observed to be associated with these freckled regions. Tensile ductility can drop to below $3 \%$ with an associated significant decrease in tensile ultimate strength. The fracture toughness can also be reduced by as much as $50 \%$ and significant increases in the crack growth rate have also been observed in freckled specimens ${ }^{(6)}$. 


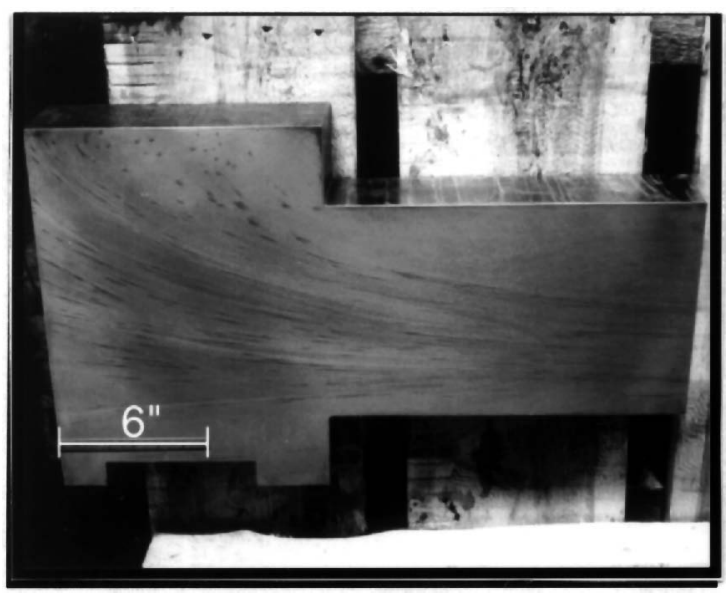

Cross-section of forging

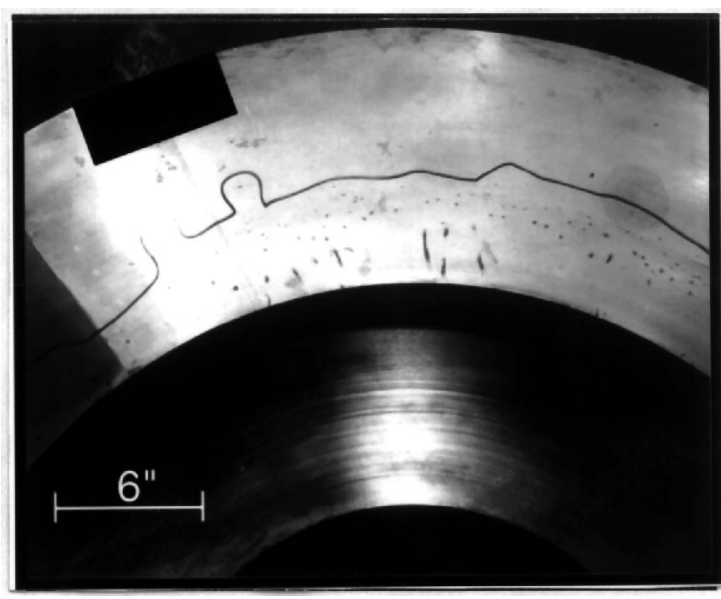

Surface of forging

Figure 1: Macro etched alloy 706 forging showing freckles.

Table II: Chemistry of freckle and alloy matrix by electron microprobe analysis

\begin{tabular}{|l|l|l|l|}
\hline Element & $\%$ in Laves Phase & $\%$ in Freckle Matrix & $\%$ in alloy \\
\hline $\mathrm{Fe}$ & 26 & 39 & 42 \\
\hline $\mathrm{Ni}$ & 26 & 41 & 39 \\
\hline $\mathrm{Cr}$ & 8 & 15 & 15 \\
\hline $\mathrm{Cb}$ & 35 & 2.9 & 2.1 \\
\hline $\mathrm{Ti}$ & 2.5 & 2.4 & 1.8 \\
\hline $\mathrm{Si}$ & 2.3 & 0.3 & 0.2 \\
\hline
\end{tabular}

Double melted VIM/VAR material has two principal disadvantages. First, the VIM electrode used in the VAR process contains many defects such as cracks and porosity that may cause excessive melt rate excursions to occur during the VAR process. These melt rate excursions can cause freckles to form in the solidifying ingot. Second, without an ESR re-melting step there is no refinement of the alloy and the sulfur content will be higher than with ESR re-melted material.

Because of these limitations with double melted alloy 706 material, it was decided to use the triple melting process (VIM/ESR/VAR) for the turbine wheels and spacers in F class machines.

\section{Compositional and Process Optimization}

\section{Compositional}

During the early stages of alloy 706 development for large land based gas turbine applications it was recognized that the wide alloy compositional limits proposed by Eiselstein and Tillack (1) needed to be optimized to achieve the best combination of mechanical properties and producibility for large forgings. It was found that the variation in chemistry within the old limits resulted in unacceptable variation in toughness, ductility, and yield strength ${ }^{(3)}$. During this time all forgings produced were carefully monitored and statistical analysis was done to optimize the compositional specification for large alloy 706 forgings. The major modifications to the alloy chemistry limits are described below. 
Silicon. The maximum allowable silicon level was reduced to $0.10 \%$. This is because studies had show that the presence of silicon promotes the formation of laves phase ${ }^{(8,9)}$. It was found that Laves phase forms at the relatively lower cooling rates at the center of large forgings. Laves can produce a large decrease in tensile ductility and toughness ${ }^{(10)}$. The precipitation of Laves phase is virtually eliminated by decreasing the silicon in alloy 706 to below $0.10 \%$.

Columbium \& Titanium. Changes in the levels of $\mathrm{Cb}$ and $\mathrm{Ti}$ affect the solvus temperature for eta phase. Eta phase at grain boundaries can reduce tensile ductility and toughness. Increasing levels of $\mathrm{Cb}$ promote the tendency for the alloy to form freckle defects during solidification. By optimizing levels of $\mathrm{Cb}$ and $\mathrm{Ti}$ a good balance of strength and toughness can be achieved while reducing scatter in mechanical properties. The maximum level of $\mathrm{Ti}$ was reduced from $2.0 \%$ to $1.8 \%$ and the $\mathrm{Cb}$ range was narrowed from $2.5-3.3 \%$ to $2.8-3.2 \%$.

Carbon. Toughness, a critical property for turbine wheels, is affected by carbon content. Laboratory studies in alloy 706 showed that significant improvements in toughness could be obtained when the carbon level was reduced from a max level of $.06 \%$ to $.02 \%$. Reduced carbon also improves machinability through reduction of the number and size of carbides formed.

Sulfur. Sulfur forms a complex sulfide in alloy 706 that can have deleterious effects on mechanical properties. It was found that low axial strength, ductility, and Charpy energy were observed (3). The cause was the presence of $(\mathrm{Ti}, \mathrm{Cb})_{2} \mathrm{CS}$, a deformable phase that can cause reduced properties in the transverse direction of forgings. Therefore the sulfur level was reduced to $<20$ ppm.

Oxygen and Nitrogen. Minimizing the oxygen and nitrogen in alloy 706 limits the amount of nitrides and oxides inclusion clusters that can form. The oxides and nitride clusters can reduce LCF life since they can be sites for LCF initiation. The level of oxygen is typically held below $10 \mathrm{ppm}$ and nitrogen is typically held below $40 \mathrm{ppm}$ to achieve a significant benefit.

\section{Processing}

The mechanical properties of alloy 706 forgings can be modified through changes in thermomechanical processing. The microstructure of alloy 706 forgings has a significant effect on mechanical properties. Toughness and LCF life can be significantly improved through improvements in grain size. The grain size improvement can be achieved through proper selection of forging and heat treatment parameters. It is important to understand the effects of cach step in the process, in order to optimize the final forged microstructure. To help achieve this understanding, laboratory studied must be coupled with deformation modeling to develop correlation between microstructure and local deformation conditions. Modeling is also used to determine the required forging loads for a specific process. This is important because GE gas turbine forgings are very large and the press capacity must be carefully considered. GE Power Systems has worked closely with each of its alloy 706 forging suppliers to help them optimize the processing of these large forgings with the specific processing equipment and processing parameters that they have chosen to produce these forgings. The common improvements in processing that have been achieved over the years are described below. 


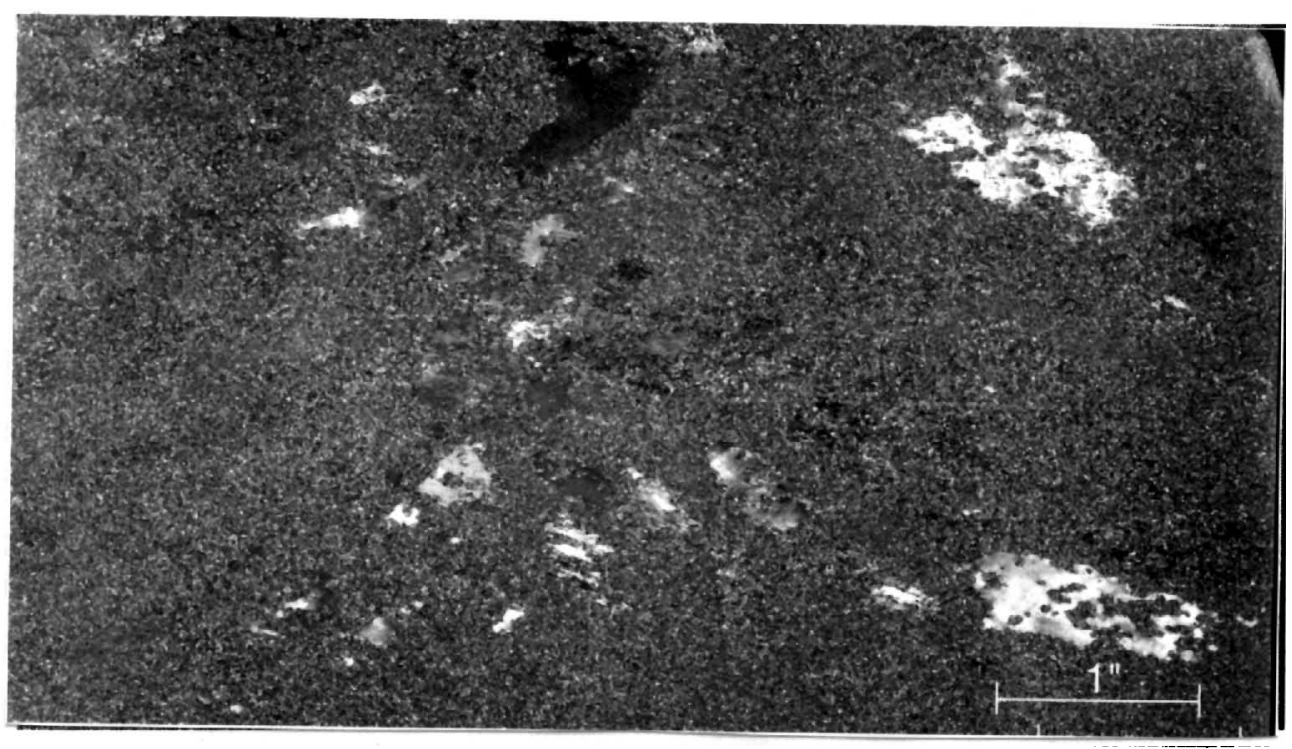

Figure 2: Alloy 706 forging with coarse grains

Billitizing. The billitizing step is critical to achieving the desired final forging microstructure. After careful cleaning and cropping of the cast ingot, the ingot must be billitized in such a way as to break-up the as-cast ingot structure and create a relatively uniform grain size so that the subsequent forging process will yield a uniform grain structure through out the forging. It was found early in the processing of these large ingots that it is necessary to utilize multiple upset and draw operations to break up the as-cast ingot structure. Ingots that do not receive sufficient work in the billitizing step can have large dendritic structures and large grains (>ASTM 0) in the final forging, Figure 2. These large grains can cause a significant decrease in the LCF properties of the forging and degrade the ultrasonic inspection capability by producing high levels of noise when the part is inspected.

\section{Forging \& Heat Treatment}

The exact forging and heat treating sequence that each forging supplier uses is dependent on the equipment and facilities that they have. GE Power Systems has conducted small scale deformation experiments on alloy 706 to help understand the effects of the forging variables on the final product microstructure (1). The following information is based upon these studies and general observations.

- The grain size after heat treatment is dependent only on the solution temperature and is independent of the deformation temperature.

- A minimum strain (at $1037 \mathrm{C}$ of 0.15 ) is needed to achieve full static recrystallization when subsequently heat-treated above $954 \mathrm{C}$.

- Multiple upsets with decreasing temperatures and intermediate recrystallization can refine the grain size of alloy 706. 
- The grain growth of alloy 706 is very rapid above $1093 \mathrm{C}$. However, at $982 \mathrm{C}$ it takes more than 30 minutes at temperature for grains to start growing. Therefore lower forging temperatures are recommended.

- A direct heat treatment after forging will minimize the time for heat up of large parts and thereby reduce grain growth.

- No dynamic recrystallization occurs if alloy 706 is forged below the eta solvus ( $970^{\circ} \mathrm{C}$ ). Therefore this is not an effective method to produce a fine grain forging as in alloy 718 .

Because F class turbine wheels are very large superalloy forgings with section thickness' exceeding 16 in., particular attention must be paid to the heating and cooling of these parts to prevent cracking due to thermal stresses. Finite element modeling was done to determine the appropriate heating and cooling conditions to minimize thermal stresses. It has also been found that if the forgings are machined prior to solution heat treatment, any high stress concentrations or surface cracks present on the forging surface must be eliminated. This will reduce the potential for cracking during the subsequent heat treatment.

Turbine wheels are given a combination recrystallization/solution treatment following forging. This is necessary because there is no dynamic recrystallization during forging for alloy 706 . The optimum treatment temperature is around $1800 \mathrm{~F}(982 \mathrm{C})$ just above the eta solvus ( $970 \mathrm{C})$. At this temperature all of the grains recrystallize, but excessive grain growth is avoided. Below $\sim 1750 \mathrm{~F}(954 \mathrm{C})$, recrystallization may not be complete and eta phase may exist at grain boundaries or within grains. Fast cooling from the solution heat treatment (water or oil quenching) is recommended to prevent precipitation of eta or laves phase in the deep-seated regions of large forgings. Fast cooling also limits the time at solution temperature, thereby minimizing grain growth.

Eiselstein documented two possible aging heat treatments for alloy 706 . The first (1350 F (732 C), followed by $1150 \mathrm{~F}(620 \mathrm{C})$ ) optimizes tensile properties while the second, a three stage aging process $(1550 \mathrm{~F}(845 \mathrm{C}), 1325 \mathrm{~F}(720 \mathrm{C}), 1150 \mathrm{~F}(620 \mathrm{C}))$, optimizes high temperature properties. The two step aging process was selected for use in GE Gas Turbines.

\section{Machining}

It has long been recognized that improper machining of superalloys can cause significant degradation of fatigue strength ${ }^{(12)}$. Alloy 706 is no exception to this rule. GE Power Systems has conducted a significant program to evaluate the effect of machining parameters on the forged alloy fatigue properties and the residual stresses. These studies have resulted in a machining specification that controls the feeds, speeds, tool types, and hole drilling parameters to avoid reduction of the fatigue properties.

\section{$\underline{\text { Ultrasonic Inspection }}$}

Concurrent with the introduction of alloy 706 into turbine wheel application, special ultrasonic examination methods and equipment were developed to optimize the inspection of these large parts ${ }^{13)}$. Since these techniques were initially developed there has been a significant improvement and refinement of the ultrasonic inspection equipment and software used to inspect these forgings. The equipment used today is fully automated and not only records indications, but also analyzes the signals to determine the nature of the indication, it's size. 
location, and if it meets the current specification requirement for that part and location. A proprietary GE software program was developed to greatly reduce the apparent noise in these forgings and enable the detection of much smaller indications than had previously been possible. This improvement has made it possible to detect indicators $1 / 2$ of the previously detectable size in alloy 706.

\section{Future Directions}

Since the deregulation of the electrical power production in the US a few years ago, there has been a realization that only power plants that can operate efficiently will be profitable and will be able to survive in this new economic environment. As a result, existing utilities and new independent power producers have been adding new, more efficient, combined cycle power plans to their generating capacity. In addition, new more efficient gas turbines have been developed such as the "H" machine and more recently the "FB" machine. These machines will provide further increases the efficiency of combined cycle power generation and also require the use of alloy 706 and 718 in the turbine rotor.

\section{GT Growth}

The growth in firing temperature and efficiency for large land-based gas turbines made by GE Power Systems is shown in Figure 3. Since the " $F$ " machine was introduced the firing

Figure 3: History of Combined Cycle Efficiency

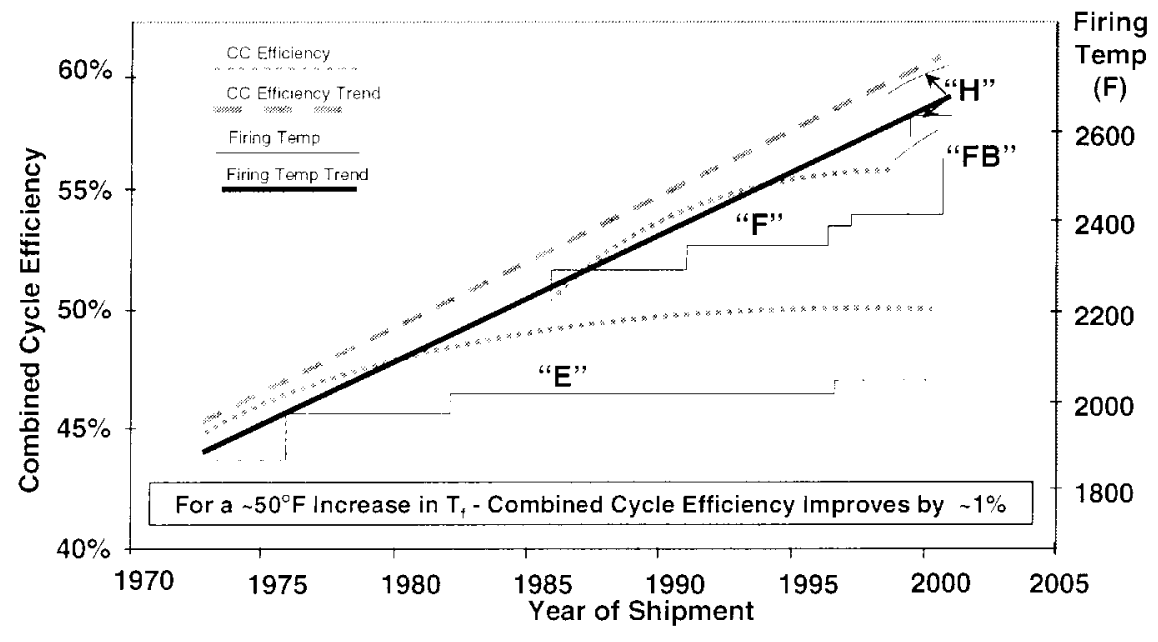

temperature has been steadily increased to improve combined cycle efficiency. The firing temperature increase from an introductory rating of $2250 \mathrm{~F}(1230 \mathrm{C})$ to more than $2400 \mathrm{~F}(1310$ C) has been achieved with improvements to the turbine section such as improved cooling schemes for the turbine buckets and nozzles, improved protective coatings and new thermal barrier coatings. Because the compressor discharge temperature and turbine exit annulus areas have not been changed, alloy 706 was able to continue to meet the requirements on these uprated " $F$ " machines. However, the new " $\mathrm{H}$ " and "FB" machines with firing temperatures greater than $2550 \mathrm{~F}(1400 \mathrm{C})$, increased compression ratios (higher compressor discharge temperatures), and larger last stage buckets (increased turbine exit annulus area) will require the use of a more capable material, alloy $718^{(+)}$. 


\section{Alloys for Rotors}

The development of large alloy 718 forgings for the new " $\mathrm{H}$ " machine has been described by Schwant et al. (4). This alloy was a logical choice because it satisfied the needs of the mechanical design for the " $\mathrm{H}$ " machine, it had the potential for large size forging producibility (slow aging kinetics), and it was a well-understood alloy with excellent experience. The challenge to produce the very large size ingots $(\sim 27$ in. $(\sim 690 \mathrm{~mm})$ in diameter and $\sim 20,000$ lbs. $(9,000 \mathrm{~kg})$.$) required for the " \mathrm{H}$ " machine, billitize these ingots and produce large forgings was successfully met. More than 20 large 718 forgings have now been produced.

The new "FB" machine recently announced by GE Power Systems also required an alloy with more capability than 706 for the turbine wheel application. The logical choice was alloy 718 since it had already been demonstrated that forgings large enough for the 7FB machine could be successfully produced. This new machine will use a combination of alloy 706 in the turbine spacers and alloy 718 in the turbine wheels. GE Power Systems is currently developing the 50 hertz (frame size 9) version of this new "FB" machine that will require a significant scale-up in size of these 718 forgings. This work is well underway and looks very promising.

There will no doubt be more advanced gas turbines beyond these current machines that will require additional capability in the turbine rotor components. The Department of Energy has identified a major initiative for the future called "Next Generation Gas Turbine Systems" that has as it's goals; improved net system efficiency, reduced cost of electricity, improved service life, reduction in emissions, and capability to use multiple fuels. A study program is already underway at GE Power Systems and several other manufacturers to identify the best 30 to 150 megawatt or larger machine configurations and cycles to meet these goals.

The next generation of materials for gas turbine rotor components will need to offer incremental improvements in strength, both tensile and fatigue, will have to be producible in large sizes, and must be microstructurally stable over the expected life of these components $(>100,000 \mathrm{hrs}$.). GE Power Systems is already working with alloy producers on new melting processes and compositions that may be required. However, significant additional compositional and processing work needs to be done to bring the next generation of turbine alloys to fruition.

\section{Conclusions}

Alloy 706 has been successfully used in large land-based heavy-duty gas turbine components for more than 12 years. Its excellent chemistry balance has allowed very large ingots to be produced and forged into high-quality turbine wheel and spacer forgings. More than 1,500 of these forgings have been applied to the new GE series of " $F$ " class gas turbines. It is estimated that more than 25 million lbs. of alloy 706 has been melted for gas turbine application and this number is rapidly increasing. Since the initial application of alloy 706 turbine forgings, some wheels have accumulated more than 58,000 hours of successful operation. More recently alloy 718 has also been successfully scaled-up and high quality turbine wheel forgings up to $\sim 80$ in. $(\sim 2000 \mathrm{~mm})$ in diameter are now in production. Freckle-free $\sim 27$ in. $(\sim 690 \mathrm{~mm})$ diameter ingots weighing up to $\sim 20,000 \mathrm{lb}$. $(\sim 9000 \mathrm{~kg})$ have been produced and larger ingots are being developed to meet the needs of the future machines. 


\section{$\underline{\text { References }}$}

1. Eiselstein, H.L. and D.J. Tillack, "The Invention and Definition of Alloy 625," Superalloy 718,625 and Various Derivatives, (Minerals, Metals \& Materials Society, Warrendale, PA. ed. Edward A. Loria, 1991).

2. A.M. Johnson and K.E. Fritz, "Properties and Microstructure of a Large Forged Superalloy Turbine Wheel," Superalloys - Metallurgy and Manufacture, (AIME 1976), 25-35.

3. P. Schilke, J. Pepe and R. Schwant, "Alloy 706 Metallurgy and Turbine Wheel Application" , Superalloys 718, 625, 706 and Various Derivatives, (ed. E. A. Loria, TMS, 1994), 1-12.

4. R.C. Schwant et al., "Large 718 Forgings for Land Based Turbines", Superalloys 718, 625 and Derivatives, (1997), p $141-152$.

5. "Inconel Alloy 706" (Technical Brochure, International Nickel Company, Inc. 1974).

6. S.V. Thamboo, "Melt Related Defects in Alloy 706 and Their Effects on Mechanical Properties", Superalloys 718, 625, 706 and Derivatives, (1994), p 137-152.

7. S.T. Wlodek et al., "Freckles in Cast and Wrought Products", Superalloys 718, 625, 706 and Derivatives, (1994), p 167-176.

8. C. Chen et al., "A Study of Effects of Phosphorus, Sulfur, Boron and Carbon on Laves and Carbide Formation in Alloy 718", Superalloys 718, 625 and Derivatives, (1991), p81-96.

9. J. P. Fesland et al., "Manufacturing Alloy 706 Forgings", Superalloys 718, 625, 706 and Derivatives, (1994), p 229-238.

10. S. V. Thamboo, et al., "Large Forgings Of Alloy 706 And Alloy 718 For Land Based Gas Turbines" (14th International Forge Master Meeting Weisbaden, September 2000), p 330335.

11. S.V. Thamboo, "Thermomechanical Behavior and Microstructure Development of Alloy 706", Superalloys 718, 625,706 and Derivatives, (1997), p 211-217.

12. G. Bellows \& R.N. Niemi (GEAE), "Surface Integrity of Machining Inconel 718 Alloy", (Soc. of Manufacturing Engineers, Creative Manufacturing Engineering Programs, Circa 1971).

13. R.V. Falsetti, "Ultrasonic Inspection of Acoustically Noisy Materials", Review of Progress in Quantitative Nondestructive Evaluation (Vol. 14B), (1995), p 2399 - 2404.

14. R.V. Falsetti, "Ultrasonic Inspection of Large Inconel 706 Forgings," (Paper presented at the ASNT Fall Conference Program Summary, 1993), 139-141. 